\title{
Higher order aberrations in amblyopic children and their role in refractory amblyopia
}

\author{
Aberrações de alta ordem em crianças com \\ ambliopia e seu papel na ambliopia refratária
}

Arnaldo Dias-Santos ${ }^{1}$, Rita Rosa', Joana Ferreira', João P. Cunha ${ }^{1}$, Cristina Brito ${ }^{1}$, Ana Paixão ${ }^{1}$, Alcina Toscano

\begin{abstract}
Objective: Some studies have hypothesized that an unfavourable higher order aberrometric profile could act as an amblyogenic mechanism and may be responsible for some amblyopic cases that are refractory to conventional treatment or cases of "idiopathic" amblyopia. This study compared the aberrometric profile in amblyopic children to that of children with normal visual development and compared the aberrometric profile in corrected amblyopic eyes and refractory amblyopic eyes with that of healthy eyes. Methods: Cross-sectional study with three groups of children - the CA group (22 eyes of 11 children with unilateral corrected amblyopia), the RA group (24 eyes of 13 children with unilateral refractory amblyopia) and the $C$ group (28 eyes of 14 children with normal visual development). Higher order aberrations were evaluated using an OPD-Scan III (NIDEK). Comparisons of the aberrometric profile were made between these groups as well as between the amblyopic and healthy eyes within the CA and RA groups. Results: Higher order aberrations with greater impact in visual quality were not significantly higher in the CA and RA groups when compared with the $\mathrm{C}$ group. Moreover, there were no statistically significant differences in the higher order aberrometric profile between the amblyopic and healthy eyes within the CA and RA groups. Conclusions: Contrary to lower order aberrations (e.g., myopia, hyperopia, primary astigmatism), higher order aberrations do not seem to be involved in the etiopathogenesis of amblyopia. Therefore, these are likely not the cause of most cases of refractory amblyopia.
\end{abstract}

Keywords: Amblyopia; Children; Refractory amblyopia; Wavefront aberrometry

\section{RESUMO}

Objetivo: Alguns estudos levantaram a hipótese de que um perfil aberrométrico de alta ordem desfavorável poderia ser um fator ambliogênico, responsável por certos casos de ambliopia "idiopática" ou refratária ao tratamento convencional. Este trabalho tem como objetivos: 1) comparar o perfil aberrométrico de crianças amblíopes com o de crianças com desenvolvimento visual normal;2) comparar a aberrometria de olhos amblíopes tratados com sucesso/curados e olhos amblíopes refratários ao tratamento convencional com a aberrometria de olhos saudáveis. Métodos: Estudo transversal com três grupos de crianças: grupo CA (22 olhos de 11 crianças com ambliopia unilateral curada), grupo RA (24 olhos de 13 crianças com ambliopia unilateral refratária) e grupo C (28 olhos de 14 crianças com desenvolvimento visual normal). Avaliou-se a aberrometria ocular total utilizando o OPD Scan-III (NIDEK). Comparou-se o perfil aberrométrico dos três grupos de estudo bem como dentro dos grupos CA e RA, o olho amblíope com o saudável. Resultados: As aberrações de alta ordem com maior impacto na qualidade visual não foram significativamente superiores nos grupos CA e RA, comparativamente ao grupo C. Por outro lado, não se encontraram diferenças estatisticamente significativas entre o perfil aberrométrico de alta ordem dos olhos amblíopes e dos olhos sãos dentro dos grupos CA e RA. Conclusão: Contrariamente às aberrações de baixa ordem (miopia, hipermetropia, astigmatismo primário), as de alta ordem não parecem relacionar-se com a etiopatogênese da ambliopia. É também pouco provável que estas sejam a causa da maioria dos casos de ambliopia refratária.

Descritores: Ambliopia; Crianças; Ambliopia refratária; Aberrometria wavefront

\footnotetext{
${ }^{1}$ Medical Doctors in Centro Hospitalar de Lisboa Central - Lisboa, Portugal;

This study was performed at Centro Hospitalar de Lisboa Central - Lisboa, Portugal;

This work was accepted for presentation as a free paper at the European Society of Ophthalmology Congress 2013 in Copenhagen.
}

The authors declare no conflicts of interest.

Recebido para publicação em 2/5/2013 - Aceito para publicação em 16/11/2013 


\section{INTRODUCTION}

A mblyopia is defined as a decrease in bestcorrected visual acuity due to some form of visual deprivation or abnormality of binocular interaction in the absence of any identifiable pathology of the eye or visual pathway. According to the classification developed by Von Noorden et al. ${ }^{(1)}$, amblyopia can be categorized into the following three types based on the causative mechanism: strabismic, refractive, and deprivation. Strabismic amblyopia is characterized by misaligned eyes, and the images from the two eyes are not capable of fusion, which leads to suppression of the visual cortex of the non-dominant eye. Refractive amblyopia includes anisometropia, bilateral high ametropia, and meridional astigmatism. Deprivation amblyopia is caused by anomalies that interfere with unilateral or bilateral visual stimuli, such as media opacities, ptosis, or occlusion.

Until a few years ago, refractive errors and aberrations were considered independent concepts. However, the modern wavefront theory combines all the optical errors and designates them together as wavefront aberrations. These, in turn, are divided into lower-order aberrations, such as myopic and hyperopic defocus and a primary astigmatism, and higher order aberrations (e.g., vertical and horizontal comas, spherical aberrations, trefoil, and tetrafoil) that cannot be corrected with spectacles or contact lenses ${ }^{(2)}$. The wavefront aberrometer is a relatively new diagnostic tool that allows us to provide a detailed description of the optical characteristics of the human eye based on complex mathematical formulas called Zernike polynomials ${ }^{(3)}$.

Recently published studies have addressed the role of using ocular aberrometry to understand the development of amblyopia. However, the results of such studies are inconsistent and contradictory. The present study is designed to compare the aberrometric profile of amblyopic children with that of children with normal visual development and to compare the aberrometry of successfully treated amblyopic eyes and amblyopic eyes refractory to conventional treatment with that of healthy eyes. Thus, we have tested the hypothesis that an unfavourable aberrometric profile can explain the lack of response to treatment in some cases of amblyopia.

\section{Methods}

The authors conducted a cross-sectional study of three groups of children recruited from the Department of Paediatric Ophthalmology and Strabismus at the Central Lisbon Hospital Centre. The CA group included 22 eyes of 11 children with unilateral corrected amblyopia (i.e., 6 males and 5 females between the ages of 5 and 14 years). The RA group included 24 eyes of 13 children with unilateral refractory amblyopia (i.e., 7 males and 6 females between the ages of 5 and 16 years). The control group, i.e., the $\mathrm{C}$ group, included 28 eyes of 14 children with normal visual development (i.e., 10 males and 4 females between the ages of 5 and 15 years).

Successfully treated amblyopia (i.e., corrected amblyopia) was defined as a best corrected visual acuity (BCVA) of greater than $8 / 10(20 / 25)$, and refractory amblyopia was defined as a BCVA of less than or equal to $8 / 10$ for more than one year after standard treatment. All patients being treated for amblyopia were monitored during a minimum of four visits throughout the first year after treatment. Children who failed to meet the therapeutic regimen or missed the follow-up appointments, children with ocular pathology other than refractive errors or strabismus, those who underwent previous surgery on the cornea or lens, and those who used contact lenses were excluded from this study. Informed written parental consent was obtained.

All children underwent a complete eye examination, including an assessment of unaided visual acuity and BCVA, subjective and objective refraction following the instillation of cyclopentolate $1 \%$, ocular motility and binocular vision evaluations, and slit-lamp and dilated fundus examinations. Wavefront analysis was performed using an OPD scan-III (NIDEK, Japan), which is based on the principle of automatic retinoscopy. The aberrometric analysis was based on Zernike coefficients for a pupil diameter of $6 \mathrm{~mm}$. In this analysis, we considered the following higher order aberrations with greater impact on visual quality: $3^{\text {rd }}$ order vertical coma, $3^{\text {rd }}$ order horizontal coma, secondary astigmatism, spherical aberration, $5^{\text {th }}$ order trefoil, $5^{\text {th }}$ order vertical coma, and $5^{\text {th }}$ order horizontal $\operatorname{coma}^{(4)}$. According to Kirwan et al., higher-order aberrations in children are not significantly affected by accommodation $^{(5)}$, which is contrary to what happens in adults ${ }^{(6,7)}$. For this reason, cycloplegia was not induced when the wavefront analysis was performed.

The data was statistically analysed using the Student's $t$ test. A $p$ value of less than 0.05 was deemed statistically significant. All the results were expressed as mean \pm standard deviation.

\section{ResUlts}

The mean age in the CA group was 8.4 years, and the mean age at which the occlusion therapy for amblyopia was initiated was 4.9 years. Regarding the etiology of the condition, 6 (i.e., $55 \%$ ) had anisometropic (i.e., refractive) amblyopia and 5 (i.e., $45 \%$ ) had strabismic amblyopia. In the RA group, the mean age was 10.2 years, and the amblyopia treatment was initiated at the mean age of 4.7 years; moreover, 7 (i.e., $54 \%$ ) had anisometropic amblyopia, and 6 (i.e., 46\%) had strabismic amblyopia. The mean age in the $\mathrm{C}$ group was 10.4 years.

Table 1 and figure 1 present the mean and standard deviation of the sphere, cylinder, spherical equivalent, BCVA, and higher order aberrations for the $\mathrm{CA}$ and $\mathrm{C}$ groups. The statistical analysis revealed no statistically significant differences between these groups for any of the evaluated parameters except the $5^{\text {th }}$ order vertical coma, which proved to be higher in the $\mathrm{C}$ group $(\mathrm{p}=0.018)$.

Table 2 and figure 2 present the mean and standard deviation of the sphere, cylinder, spherical equivalent, BCVA, and higher order aberrations for the RA and $\mathrm{C}$ groups. Statistically significant differences were observed for the sphere $(\mathrm{p}=0.038)$, spherical equivalent $(\mathrm{p}=0.047)$, and BCVA $(\mathrm{p}=0.000)$, all of which were larger in the refractory amblyopic group. No statistically significant differences were observed for the cylinder or for any of the higher order aberrations.

Table 3 and figure 3 compare the corrected-amblyopic (i.e., the successfully treated eye) with the healthy eye in the CA group. Statistically significant differences were observed between the two eyes for the cylinder $(\mathrm{p}=0.023)$ and the BCVA $(\mathrm{p}=0.024)$.

Table 4 and figure 4 compare the refractory-amblyopic eye with the healthy eye in the RA group. Statistically significant differences between the two eyes were observed for the sphere $(\mathrm{p}=0.038)$, cylinder $(\mathrm{p}=0.030)$, and BCVA $(\mathrm{p}=0.000)$. 
Table 1

\section{Comparison of the CA and C groups in terms of the BCVA, refractive study (expressed in diopters) and wavefront analysis (Zernike coefficients)}

\begin{tabular}{lccr}
\hline Variables & CA group & C group & p value \\
\hline Sphere & $3.38 \pm 2.74$ & $1.80 \pm 3.07$ & 0.069 \\
Cylinder & $1.67 \pm 1.11$ & $1.30 \pm 1.23$ & 0.192 \\
Spherical equivalent & $3.73 \pm 3.31$ & $2.13 \pm 3.49$ & 0.095 \\
BCVA & $0.98 \pm 0.05$ & $0.99 \pm 0.05$ & 0.271 \\
$3^{\text {rd }}$ order vertical coma & $0.15 \pm 0.16$ & $0.19 \pm 0.22$ & 0.305 \\
$3^{\text {rd }}$ order horizontal coma & $0.10 \pm 0.07$ & $0.11 \pm 0.10$ & 0.368 \\
Secondary astigmatism & $0.05 \pm 0.06$ & $0.07 \pm 0.05$ & 0.109 \\
Spherical aberration & $0.10 \pm 0.09$ & $0.12 \pm 0.11$ & 0.282 \\
$5^{\text {th }}$ order trefoil & $0.03 \pm 0.04$ & $0.04 \pm 0.03$ & 0.280 \\
$5^{\text {th }}$ order vertical coma & $0.02 \pm 0.02$ & $0.04 \pm 0.03$ & $0.018^{*}$ \\
$5^{\text {th }}$ order horizontal coma & $0.03 \pm 0.02$ & $0.03 \pm 0.04$ & 0.265 \\
\hline
\end{tabular}

* Statistically significant difference $(\mathrm{p}<0.05)$

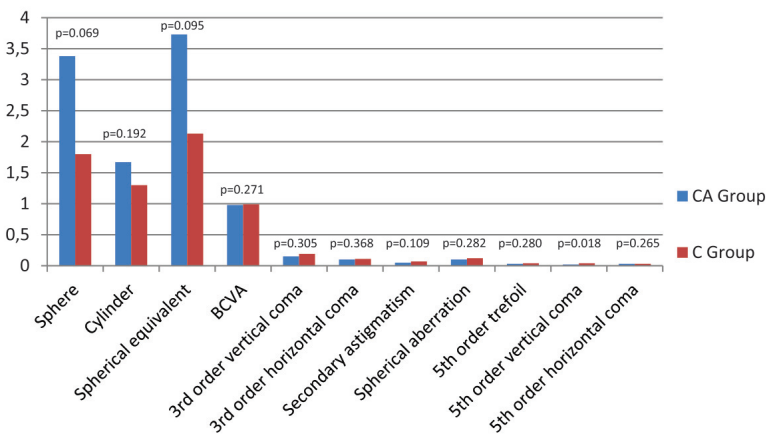

Figure 1: Comparison of the CA and C groups in terms of the BCVA, refractive study (expressed in diopters), and wavefront analysis (Zernike coefficients)

\section{Discussion}

Over the last few years, the impact of higher order aberrations on visual development and emmetropization has been the source of much debate. Brunette et al. described significant levels of higher order aberrations in children, but these higher order aberrations tended to decrease with growth, possibly as part of emmetropization ${ }^{(8)}$. Studies have shown that lower order aberrations are responsible for about $90 \%$ of the quality of retinal images and that the remaining $10 \%$ is a combination of the effects of various higher order aberrations ${ }^{(9)}$. However, higher order aberrations do not interact with each other in a linear algebraic manner ${ }^{(10,11)}$; in fact, the effects of the different aberrations tend to compensate for each other ${ }^{(4,12)}$. According to the work of Kelly et al., corneal optical aberrations are often compensated by internal ocular aberrations; therefore, the measurement of corneal wavefront aberrometry alone may produce inaccurate information about the retinal image quality ${ }^{(12)}$. Performing both corneal and total ocular aberrometry may also help in the diagnosis of subtle corneal or lenticular imperfections that can easily go undetected during the slit lamp exam. Normal corneal topography and elevation maps with high
Table 2

\section{Comparison of the RA and C groups in terms of the BCVA, refractive study (expressed in dioptres), and wavefront analysis (Zernike coefficients)}

\begin{tabular}{lccr}
\hline Variables & RA group & C group & p value \\
\hline Sphere & $3.08 \pm 1.89$ & $1.80 \pm 3.07$ & $0.038^{*}$ \\
Cylinder & $1.46 \pm 1.10$ & $1.30 \pm 1.23$ & 0.308 \\
Spherical equivalent & $3.53 \pm 2.30$ & $2.13 \pm 3.49$ & $0.047 *$ \\
BCVA & $0.75 \pm 0.28$ & $0.99 \pm 0.05$ & $0.00 *^{*}$ \\
$3^{\text {rd }}$ order vertical coma & $0.22 \pm 0.21$ & $0.19 \pm 0.22$ & 0.300 \\
$3^{\text {rd }}$ order horizontal coma & $0.13 \pm 0.14$ & $0.11 \pm 0.10$ & 0.230 \\
Secondary astigmatism & $0.43 \pm 1.78$ & $0.07 \pm 0.05$ & 0.067 \\
Spherical aberration & $0.11 \pm 0.11$ & $0.12 \pm 0.11$ & 0.396 \\
$5^{\text {th }}$ order trefoil & $0.63 \pm 2.77$ & $0.04 \pm 0.03$ & 0.057 \\
$5^{\text {th }}$ order vertical coma & $0.21 \pm 0.84$ & $0.04 \pm 0.03$ & 0.147 \\
$5^{\text {th }}$ order horizontal coma & $0.08 \pm 0.28$ & $0.03 \pm 0.04$ & 0.178 \\
\hline
\end{tabular}

* Statistically significant difference $(\mathrm{p}<0.05)$

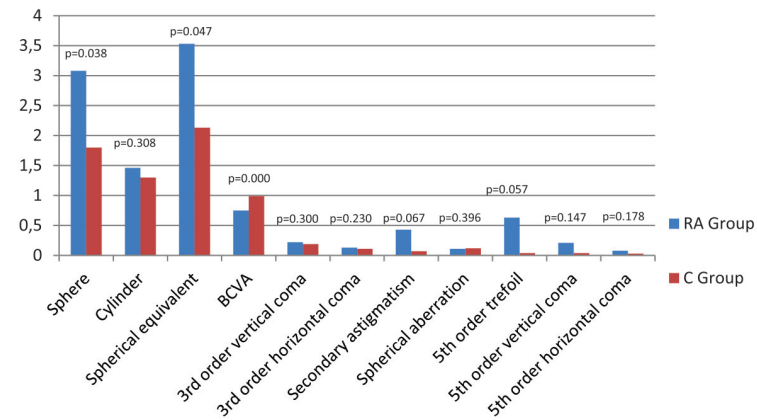

Figure 2: Comparison of the RA and $\mathrm{C}$ groups in terms of the BCVA refractive study (expressed in diopters), and wavefront analysis (Zernike coefficients)

total-eye aberrations suggest the lens as the probable source of aberrations. In fact, an abnormal total-eye aberrometric profile can be the first diagnostic clue of subtle lenticonus as the main cause of reduced visual acuity. In this particular case there will be ocular spherical aberration predominance with normal or nearnormal corneal maps. In keratoconic eyes coma-like corneal aberration will predominate ${ }^{(13-15)}$.

An asymmetric congenital or early onset aberrometric pattern could reasonably promote the development of early ocular dominance. This phenomenon could be responsible for some cases of "idiopathic" amblyopia or lead to refractory amblyopia if such an aberrometric pattern coexists with other treatable causes of amblyopia. Zhau et al. reported an association between the vertical coma, 5th order aberrations and refractory amblyopia $^{(2)}$. Plech et al. studied the relationship between the corneal wavefront analysis and amblyopia in adults. Although they found a higher prevalence of coma in amblyopic adults, this difference was not statistically significant ${ }^{(16)}$. On the other hand, Kirwan et al. studied the total aberrometric profile in children with strabismic and anisometropic amblyopia and concluded that unlike the lower order aberrations, the higher order aberrations did not differ significantly from normal eyes, thereby casting doubt on their amblyogenic potential ${ }^{(17)}$. 
Table 3

BCVA, refractive study (expressed in diopters) and wavefront analysis (Zernike coefficients) to compare the corrected-amblyopic eye with the healthy eye for children in the CA group

\begin{tabular}{lcrr}
\hline Variables & $\begin{array}{c}\text { Corrected- } \\
\text { amblyopic eye }\end{array}$ & Healthy eye & p value \\
\hline Sphere & $4.63 \pm 2.97$ & $2.13 \pm 2.00$ & 0.059 \\
Cylinder & $2.29 \pm 1.12$ & $1.04 \pm 0.73$ & $0.023^{*}$ \\
Spherical equivalent & $5.10 \pm 3.69$ & $2.36 \pm 2.45$ & 0.080 \\
BCVA & $0.95 \pm 0.05$ & $1.00 \pm 0.00$ & $0.024^{*}$ \\
$3^{\text {rd }}$ order vertical coma & $0.13 \pm 0.11$ & $0.17 \pm 0.20$ & 0.298 \\
$3^{\text {rd }}$ order horizontal coma & $0.07 \pm 0.06$ & $0.13 \pm 0.08$ & 0.063 \\
Secondary astigmatism & $0.04 \pm 0.03$ & $0.06 \pm 0.07$ & 0.140 \\
Spherical aberration & $0.07 \pm 0.08$ & $0.13 \pm 0.10$ & 0.100 \\
$5^{\text {th }}$ order trefoil & $0.03 \pm 0.04$ & $0.03 \pm 0.03$ & 0.496 \\
$5^{\text {th }}$ order vertical coma & $0.01 \pm 0.02$ & $0.03 \pm 0.03$ & 0.122 \\
$5^{\text {th }}$ order horizontal coma & $0.01 \pm 0.01$ & $0.04 \pm 0.03$ & 0.060 \\
\hline
\end{tabular}

(*) Statistically significant difference $(\mathrm{p}<0.05)$

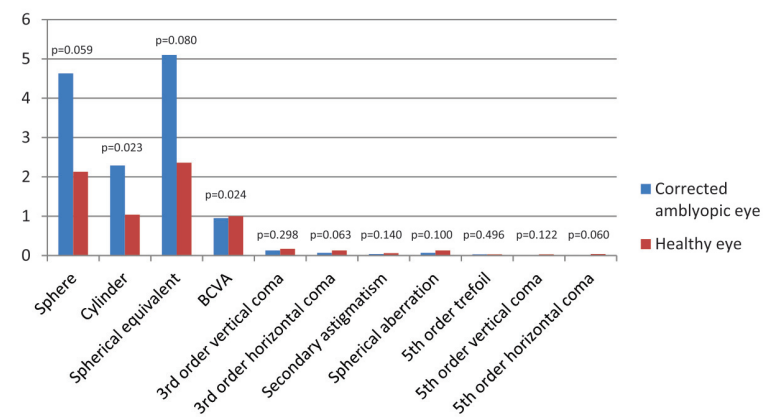

Figure 3: BCVA, refractive study (expressed in diopters), and wavefront analysis (Zernike coefficients) to compare the correctedamblyopic eye with the healthy eye for the children in the CA group

In this work, the refractive and aberrometric profiles of corrected-amblyopic and healthy children were compared. A statistically significant difference was observed only for the $5^{\text {th }}$ order vertical coma, which was surprisingly higher in the control group $(C)$.

A comparison of the refractive and aberrometric profiles of refractory-amblyopic and healthy children revealed statistically significant differences for the sphere, spherical equivalent, and BCVA. The higher order aberrations were globally larger in the refractory-amblyopic group; however, this difference was not statistically significant.

Within the CA group, the comparison between the amblyopic and the healthy eyes revealed statistically significant differences only for the cylinder and BCVA. Within the RA group, the comparison between the amblyopic and the healthy eyes revealed statistically significant differences only for the sphere, cylinder and BCVA.

The design of this study differs from that of other published studies by allowing not only the assessment of the aberrometric profile of children with successfully treated and refractory amblyopia but also including the comparison of the aberrometric profile of the amblyopic eyes to that of the healthy eyes within
Table 4

BCVA, refractive study (expressed in diopters) and wavefront analysis (Zernike coefficients) to compare the refractory-amblyopic eye with the healthy eye for children in the RA group

\begin{tabular}{llrr}
\hline Variables & \multicolumn{2}{c}{$\begin{array}{c}\text { Refractory- Healthy eye } \\
\text { amblyopic eye }\end{array}$} & p value \\
\hline Sphere & $3.73 \pm 1.75$ & $2.42 \pm 1.85$ & $0.038^{*}$ \\
Cylinder & $1.87 \pm 1.16$ & $1.06 \pm 0.90$ & $0.030^{*}$ \\
Spherical equivalent & $4.13 \pm 2.37$ & $2.94 \pm 2.14$ & 0.096 \\
BCVA & $0.53 \pm 0.23$ & $0.98 \pm 0.06$ & $0.000^{*}$ \\
$3^{\text {rd }}$ order vertical coma & $0.19 \pm 0.15$ & $0.24 \pm 0.27$ & 0.293 \\
$3^{\text {rd }}$ order horizontal coma & $0.14 \pm 0.14$ & $0.12 \pm 0.14$ & 0.351 \\
Secondary astigmatism & $0.07 \pm 0.09$ & $0.79 \pm 2.49$ & 0.083 \\
Spherical aberration & $0.11 \pm 0.12$ & $0.11 \pm 0.10$ & 0.479 \\
$5^{\text {th }}$ order trefoil & $0.08 \pm 0.15$ & $1.17 \pm 3.87$ & 0.087 \\
$5^{\text {th }}$ order vertical coma & $0.05 \pm 0.04$ & $0.37 \pm 1.19$ & 0.179 \\
$5^{\text {th }}$ order horizontal coma & $0.02 \pm 0.02$ & $0.14 \pm 0.40$ & 0.161 \\
\hline
\end{tabular}

(*) Statistically significant difference $(\mathrm{p}<0.05)$

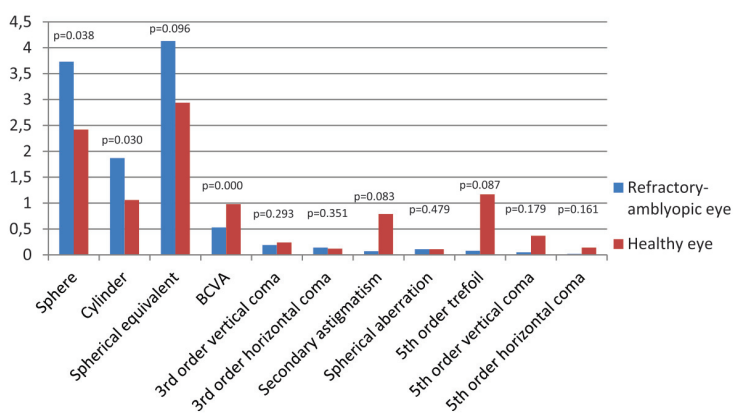

Figure 4: BCVA, refractive study (expressed in diopters), and wavefront analysis (Zernike coefficients) to compare the refractory-amblyopic eye with the healthy eye for children in the RA group

these groups of children. Thus, we studied the hypothesis that had already been raised by other authors ${ }^{(2,18)}$; i.e., an unfavourable wavefront aberrometric profile could be a major indicator of treatment failure for either refractive or strabismic amblyopia. However, the results of this work do not corroborate that hypothesis. Moreover, this analysis did not reveal a higher prevalence of higher order aberrations in children with strabismic or anisometropic amblyopia as compared to normal children. Nevertheless, we do not completely reject the hypothesis that higher order aberrations could be a contributing factor for abnormal visual development in some isolated published case reports ${ }^{(19)}$. However, this does not appear to be a major factor in the pathogenesis of amblyopia; therefore, treatment should continue to focus on the correction of strabismus, refractive errors, and the causes of deprivation amblyopia whenever possible in conjunction with occlusion or pharmacologic penalization of the healthy eye.

Three major types of factors limit the maximum resolution power of the human eye, i.e., retinal, neural, and optical factors. The latter includes dispersion, diffraction, chromatic, and monochromatic aberrations (i.e., wavefront aberrometers only 
measure monochromatic aberrations). Future studies focused on these three major factors may provide further explanations regarding the pathophysiological mechanisms responsible for "idiopathic" and refractory amblyopia.

\section{ReFERENCES}

1. Von Noorden GK, Campos EC. Binocular vision and ocular motility: theory and management of strabismus. St. Louis: CV Mosby; 2002. p.246-86.

2. Zhao PF, Zhou YH, Wang NL, Zhang J. Study of the wavefront aberrations in children with amblyopia. Chin Med J (Engl). 2010;123(11):1431-5.

3. Lu J,Zhou YH,Zheng Y. Influence of wavefront aberration on contrast sensitivity in myopic eyes. Rec Adv Ophthalmol. 2007; 7:682-4.

4. Applegate RA, Sarver EJ, Khemsara V. Are all aberrations equal? J Refract Surg. 2002;18(5):S556-62.

5. Kirwan C, O'Keefe M, Soeldner H. Higher-order aberrations in children. Am J Ophthalmol. 2006;141(1):67-70.

6. Carkeet A, Velaedan S, Tan YK, Lee DY, Tan DT. Higher order ocular aberrations after cycloplegic and non-cycloplegic pupil dilation. J Refract Surg. 2003;19(3):316-22.

7. He JC, Burns SA, Marcos S. Monochromatic aberrations in the accommodated human eye. Vision Res. 2000;40(1):41-8.

8. Brunette I, Bueno JM, Parent M, Hamam H, Simonet P. Monochromatic aberrations as a function of age, from childhood to advanced age. Invest Ophthalmol Vis Sci. 2003;44(12):5438-46.

9. Liang J, Grimm B, Goelz S, Bille JF. Objective measurement of wave aberrations of the human eye with the use of a HartmannShack wave-front sensor. J Opt Soc Am A Opt Image Sci Vis. 1994;11(7):1949-57.

10. Alió JL, Piñero DP, Plaza Puche AB. Corneal wavefront-guided enhancement for high levels of corneal coma aberration after laser in situ keratomileusis. J Cataract Refract Surg. 2008;34(2):222-31.
11. Applegate RA, Marsack JD, Ramos R, Sarver EJ. Interaction between aberrations to improve or reduce visual performance. J Cataract Refract Surg. 2003;29(8):1487-95.

12. Kelly JE, Mihashi T, Howland HC. Compensation of corneal horizontal/vertical astigmatism, lateral coma, and spherical aberration by internal optics of the eye. J Vis. 2004;4(4):262-71.

13. Ninomiya S, Maeda N, Kuroda T, Saito T, Fujikado T, Tano Y, et al. Evaluation of lenticular irregular astigmatism using wavefront analysis in patients with lenticonus. Arch Ophthalmol. 2002;120(10):1388-93.

14. Chong EM, Wang L, Basti S, Koch DD. Anterior lenticonus detected by wavefront aberrometry. Am J Ophthalmol. 2005;140(5):921-4.

15. Xu Y, Hersh PS, Chu DS. Wavefront analysis and Scheimpflug imagery in diagnosis of anterior lenticonus. J Cataract Refract Surg. 2010;36(5):850-3.

16. Plech AR, Pinero DP, Laria C,Aleson A,Alio JL. Corneal higher-order aberrations in amblyopia. Eur J Ophthalmol. 2010;20(1):12-20.

17. Kirwan C, O'Keefe M. Higher order aberrations in children with amblyopia. J Pediatr Ophthalmol Strabismus. 2008;45(2):92-6.

18. Agarwal A, Prakash G, Jacob S, Ashokkumar D, Agarwal A. Can uncompensated higher order aberration profile, or aberropia be responsible for subnormal best corrected vision and pseudo-amblyopia. Med Hypotheses. 2009;72(5):574-7.

19. Prakash G, Sharma N, Chowdhary V, Titiyal JS. Association between amblyopia and higher-order aberrations. J Cataract Refract Surg. 2007;33(5):901-4.

\section{Corresponding author}

Arnaldo Dias-Santos

Rua Luis de Camões, n 12, ex-lote 11 Quinta Nova de São Roque 2670-513 Loures - Portugal

Telephone: 00351919273677

E-mail: arnaldomiguelsantos@ig.com.br 